WellBeing International

WBI Studies Repository

$6-2013$

\title{
Environmental Change Alters Personality in the Rainbow Trout, Oncorhynchus mykiss
}

\author{
Ashley J. Frost \\ University of Liverpool \\ Jack S. Thomson \\ University of Liverpool \\ Charlotte Smith \\ University of Liverpool \\ Hannah C. Burton \\ University of Liverpool \\ Ben Davis \\ University of Liverpool
}

See next page for additional authors

Follow this and additional works at: https://www.wellbeingintlstudiesrepository.org/acwp_asie

Part of the Animal Studies Commons, Comparative Psychology Commons, and the Other Animal Sciences Commons

\section{Recommended Citation}

Frost, A. J., Thomson, J. S., Smith, C., Burton, H. C., Davis, B., Watts, P. C., \& Sneddon, L. U. (2013).

Environmental change alters personality in the rainbow trout, Oncorhynchus mykiss. Animal Behaviour, 85(6), 1199-1207.

This material is brought to you for free and open access by WellBeing International. It has been accepted for inclusion by an authorized administrator of the WBI Studies Repository. For more information, please contact wbisr-info@wellbeingintl.org.

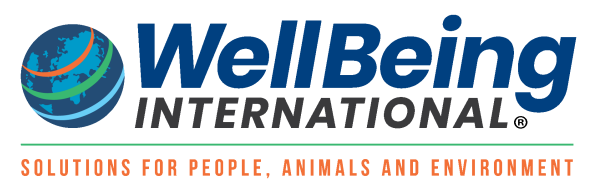




\section{Authors}

Ashley J. Frost, Jack S. Thomson, Charlotte Smith, Hannah C. Burton, Ben Davis, Phillip C. Watts, and Lynne U. Sneddon 


\title{
Environmental Change Alters Personality in the Rainbow Trout, Oncorhynchus mykiss
}

\author{
Ashley J. Frost ${ }^{1}$, Jack S. Thomson ${ }^{1}$, Charlotte Smith ${ }^{1}$, Hannah C. Burton ${ }^{1,2}$, Ben Davis ${ }^{1,3}$, \\ Phillip C. Watts ${ }^{1}$, Lynne U. Sneddon ${ }^{1,4}$ \\ 1 University of Liverpool \\ 2 Cardiff University \\ 3 James Cook University \\ 4 University of Chester
}

\section{KEYWORDS}

behavioural plasticity, boldness, coping style, hypoxia, Oncorhynchus mykiss, predation risk, rainbow trout, temperature

\begin{abstract}
Boldness is a personality trait that defines how individuals respond to risky situations and has clear fitness consequences. Since the adaptive value of boldness is context dependent, the benefit of a distinct personality is less clear when the environment is unpredictable. An ability to modulate behaviour can be beneficial, although as behavioural plasticity itself may be costly this depends on the levels of environmental stability. Both boldness and its plasticity are linked with physiological stress coping mechanisms, whereby animals with reduced glucocorticoid responses to stress are bolder and less flexible in behaviour. We investigated the behavioural changes made by bold and shy rainbow trout, and the magnitude of those changes, in response to predation risk and exposure to two environmental challenges. Behavioural and physiological responses under biotic (either no, predictable or unpredictable predation risk) and abiotic (temperature increase or hypoxia) factors were measured. Boldness was determined using a standard novel object paradigm. In general, after exposure to the treatments, fish exhibited less extreme bold or shy behaviour; the greatest change was observed in fish exposed to hypoxia, or those exposed to high risk particularly in shy fish held at a lower temperature. Higher risk also resulted in increased stress, suggesting that extreme bold or shy behaviour might have been maladaptive under a potential predator threat. These results represent novel evidence that boldness is flexible depending upon particular environmental challenges, with important implications for populations facing environmental extremes caused by anthropogenic activity and climate change.
\end{abstract}

Individuals exhibit consistent differences in response to an environmental challenge which are expressed across a range of contexts and situations. Such discrete sets of behaviour are termed behavioural syndromes or animal personalities (Dingemanse \& Réale 2005), and each individual within a species can be described as having a particular behavioural type (Sih et al. 2004). One such personality is boldness, which defines an individual's response to novelty and its propensity for taking risks: bold animals are often (although not always; reviewed in Conrad et al. 2011) more aggressive, more active and more likely 
to explore new environments or objects than shy conspecifics (Sneddon 2003; Sih et al. 2004; van Oers et al. 2005). Boldness and aggression are considered strongly linked to the magnitude to which an individual will exhibit a physiological response to any environmental challenge; such a combination of physiology and behaviour is termed coping style (Koolhaas et al. 1999). Boldness thus has important implications for fitness, both for individuals and for groups or populations, which depends upon the particular environmental contexts to which these animals are exposed (Wilson et al. 1993; Sih et al. 2004). Some individuals, however, can vary their behaviour according to prior experience (Wilson et al. 1993; Frost et al. 2007). As such, the impact of environmental conditions on individual behaviour is important as different behavioural strategies vary in their energetic and risk components according to the environmental context (Dall et al. 2004; Chapman et al. 2010). For instance, where predation is low being bold and active would result in increased feeding and growth and thus be considered adaptive, but where predators are present high activity would result in increased exposure and mortality; in this case, being shy may be more appropriate (Sih et al. 2004). However, not all personality types are capable of plasticity, with the behaviour of bold animals considered more stable than that of shy conspecifics (Koolhaas et al. 1999; Carere et al. 2005; Ruiz-Gomez et al. 2011). Intraspecific variation in boldness, and therefore behavioural plasticity, thus has implications for the survival of individuals or populations in either stable or variable environments.

Aquatic animals are naturally exposed to spatiotemporal variations in environmental quality (e.g. diel or annual changes in water temperature, and variations in water quality influenced by depth, geology and biota; Matthews \& Berg 1997), and individuals must adapt to these stressors. Hypoxia, for example, is a common seasonal and diel stressor (Bernier \& Craig 2005), and acclimation to hypoxia can be achieved through behavioural changes in the short term (Timmerman \& Chapman 2004; Herbert \& Steffensen 2005; Shingles et al. 2005), or through physiological modification when hypoxia is chronic (Timmerman \& Chapman 2004; Martínez et al. 2006). While specific responses may vary between species (Herbert \& Steffensen 2005), a compromised physiological state can limit subsequent behavioural responses to further challenges, such as predation threat (Dall et al. 2004; Shingles et al. 2005). Moreover, combinations of environmental stressors may act synergistically to elevate levels of mortality (Matthews \& Berg 1997). Anthropogenically induced elevated temperature and reduced water oxygen content are increasingly affecting animals (Timmerman \& Chapman 2004), particularly those at the edge of their physiological tolerance (e.g. Matthews \& Berg 1997; Herbert \& Steffensen 2006). Theoretical models of population and species adaptations to a rapidly changing climate need to be informed by studies into individual responses to environmental challenges; thus, in this study we examined the impact of hypoxia or increased temperature by determining how bold and shy individuals alter their propensity to take risks in the face of a novel challenge. Under these conditions fish may be metabolically compromised and may need to forage more to meet energy demands, or reduce activity to conserve energy.

Predation is a consistent threat for most animals, which have to balance activities to maximize productivity while minimizing exposure to predators, and the extent to which they do this may further be state dependent (e.g. Lima \& Bednekoff 1999; Quinn et al. 2012). Bold and shy animals exhibit fundamentally different antipredator strategies, since shy animals are reclusive and tend to take shelter when under threat, while bold animals may be more likely to spend time in the open even when dangerous to do so (Wilson et al. 1993; Sih et al. 2004). Stress, however, often has detrimental effects on physiological and behavioural systems such as impairments to cardiovascular function, energetics and locomotory or escape responses, thereby compromising an individual's ability to avoid a predator (Olla et al. 1995; Lefrancois et al. 2005). Therefore, in this study we exposed bold and shy individuals to varying risk to determine whether this influenced behavioural decisions in the face of hypoxia or increased temperature. 
Boldness is linked to the physiological stress response profiles of individuals. In teleost fish, the hypothalamo-pituitary-interrenal (HPI) axis is considered the dominant physiological stress axis, and activation results in the secretion of pituitary cortisol (Wendelaar Bonga 1997). Bold animals are considered to produce a low HPI response to stress while shy animals produce a high response, with consequences for both behaviour and its plasticity, and these are termed proactive and reactive coping styles, respectively (Koolhaas et al. 1999). Coping styles intrinsically relate the boldness aggression syndrome to the magnitude of the physiological response to stress. While coping styles have been identified in salmonids (e.g. Øverli et al. 2007; Brelin et al. 2008), the link between physiology and behaviour is not always clear, possibly representing phenotypic plasticity or decoupling of traits (Schjolden et al. 2005; Ruiz-Gomez et al. 2008; Thomson et al. 2011); further work is therefore necessary to understand fully how divergent stress responsiveness is maintained even when behaviour changes. In this study we determined cortisol concentrations to correlate this with behavioural changes within the contexts of risk and environmental variation.

Natural environments provide multiple challenges, often simultaneously, and individuals need to be able to deal with each stress appropriately. Many studies focus on one or two potential stressors, and while this provides important and useful information regarding individual responses, these studies do not necessarily reflect the complexity of natural scenarios in which organisms may often find themselves. It is imperative for studies to focus on such stressors alone or in combination to improve understanding of how organisms not only survive but also adapt to a range of natural pressures. The aims of this study were (1) to characterize the behavioural changes in bold and shy rainbow trout exposed to one or a combination of the key environmental stressors periodic risk, reduced water oxygen content and increased temperature; and (2) to quantify the association between boldness, and its plasticity, and the neuroendocrine response to stress. We used this integrative approach to determine whether divergent phenotypes would alter their behaviour in response to a risky environment, and also whether these changes might be mediated or augmented by state-imposed changes in metabolic state through hypoxia or increased temperature.

Table 1. Treatment combinations and numbers of bold and shy rainbow trout used in the study

\begin{tabular}{|c|c|c|c|c|}
\hline \multirow[t]{2}{*}{ Risk } & \multirow[t]{2}{*}{$\mathrm{O}_{2}$ saturation $(\%)$} & \multirow[t]{2}{*}{ Temperature $\left({ }^{\circ} \mathrm{C}\right)$} & \multicolumn{2}{|c|}{$N$} \\
\hline & & & Bold & Shy \\
\hline \multirow{3}{*}{ None } & 100 & 11 & 5 & 7 \\
\hline & 50 & 11 & 9 & 6 \\
\hline & 100 & 19 & 7 & 8 \\
\hline \multirow{3}{*}{ Low (predictable) } & 100 & 11 & 5 & 7 \\
\hline & 50 & 11 & 5 & 7 \\
\hline & 100 & 19 & 7 & 10 \\
\hline \multirow{3}{*}{ High (unpredictable) } & 100 & 11 & 5 & 7 \\
\hline & 50 & 11 & 13 & 5 \\
\hline & 100 & 19 & 14 & 13 \\
\hline
\end{tabular}




\section{METHODS}

Experiments were conducted with approval from the Home Office, U.K. (licence no. 40/3315) and the University of Liverpool's Ethics Committee. Rainbow trout (average weight \pm SE $=98.5 \pm 3.2 \mathrm{~g} ; N=142$ ) were obtained from a commercial supplier and maintained in stock tanks ( $2 \times 2 \mathrm{~m}$ and $0.5 \mathrm{~m}$ high) on a semi-recirculating system at $11 \pm 1^{\circ} \mathrm{C}$, with constant aeration and on a $14: 10 \mathrm{~h}$ light:-dark cycle. The trout were allowed at least 2 weeks in the stock tanks to recover from the stress of transport and used within 1 month once the stocks were readily feeding. Fish were fed commercial trout feed (Skretting, Northwich, U.K.) at $1.5 \%$ body weight per day as per manufacturer's instructions. For experiments, fish were held individually in separate glass aquaria $(90 \times 50 \mathrm{~cm}$ and $45 \mathrm{~cm}$ high) that were screened from visual disturbance and provided with filtered water and aeration; light, temperature and feeding regimes were identical to those of the stock tanks. After a 7-day acclimation period, fish were assessed for boldness before entering a 14-day test period. Fish were exposed to varying levels of predation threat, but to avoid exposure to multiple stressors simultaneously, variations in water temperature and oxygen concentration were introduced for only the second half of the trial period (Table 1).

\section{Boldness Assessments}

Boldness was assessed using a standard novel object paradigm (Wilson et al. 1993; Frost et al. 2007). Two novel objects were constructed of Lego Duplo blocks of multiple colours, and varied in construction (each approximately $10 \times 7 \mathrm{~cm}$ and $4 \mathrm{~cm}$ high) as per Sneddon et al. (2003). One object was used for the first assessment and a different object for the second test to prevent habituation (which is unlikely unless a single object is presented regularly and repeatedly; Sneddon et al. 2003). Low-light cameras were positioned at the front and sides of the tank, which was lined with rulers to allow accurate records of the proximity of the fish to the novel object in three dimensions. Fish were allowed $10 \mathrm{~min}$ to recover from the initial disturbance of starting the experimental set-up, after which time a novel object was dropped approximately $10 \mathrm{~cm}$ in front of the subject and the behaviour recorded for $10 \mathrm{~min}$.

The principal measure of bold and shy personalities was latency to approach to within $5 \mathrm{~cm}$ of the novel object. Bold fish approached within $185 \mathrm{~s}$ while shy fish approached no earlier than $270 \mathrm{~s}$; comparable threshold approach latencies have previously successfully distinguished between bold and shy personalities in rainbow trout (Frost et al. 2007; Thomson et al. 2011). Of the 70 fish classed as shy, 51 (72.3\%) did not approach the object within the $10 \mathrm{~min}$ of the trial; these fish were assigned an approach latency of $601 \mathrm{~s}$ for analysis. A few (ca. 1.4\%) fish were classed as intermediate and were not used for experiments. The duration of active behaviour, defined as the time spent swimming (at a speed no less than one body length every $2 \mathrm{~s}$ ), was also recorded. Subjects were retested for boldness after the 14-day test period with a different object to prevent habituation to a familiar shape (Sneddon et al. 2003). A control group of trout ( $\mathrm{N}=5$ bold and 7 shy) were kept at standard conditions, and received no treatments during this period, to test for behavioural consistency. Prior to the first trial, fish were anaesthetized (benzocaine, Sigma-Aldrich Co., Gillingham, U.K. at $0.033 \mathrm{~g} / \mathrm{litre}$ ) and the weight of each individual recorded.

\section{Predation Risk}

Bold and shy fish were subsequently exposed to either a low- (predictable) or a high- (unpredictable) risk regime. Low risk involved simulated predator attacks each performed at the same time each day throughout the 14-day test period. The high-risk regime consisted of an unpredictable number of simulated attacks at random each day. Predator threat was simulated using a validated protocol (Ashley et al. 2009): $15 \mathrm{ml}$ of alarm pheromone was injected into the tank followed immediately by three swift strikes into the water using a model heron, Ardea cinerea, head. The use of model predators generates 
fright responses in teleosts, including rainbow trout (Jönsson et al. 1996; Johnsson et al. 2001). Alarm pheromone elicits a similar behavioural response in fish (Smith 1992), including rainbow trout (Brown \& Smith 1997), and particularly in the context of a predator attack such as that simulated by use of a model (Wisenden et al. 2004). Pheromone was prepared from the skin of other rainbow trout as per Brown \& Smith (1998) with some minor modifications: skin washed in sterile distilled water was homogenized in $25 \mathrm{ml}$ of sterile distilled water, centrifuged at 8500 RPM for $15 \mathrm{~min}$, and the supernatant stored at $-20^{\circ} \mathrm{C}$ until the day of experimentation. Simulated attacks were performed from behind a dark screen to prevent human association. After the test period individuals were reassessed for boldness before being killed humanely (see Tissue Sampling).

Table 2. Akaike information criterion (AIC) and residual degrees of freedom (df) for full and minimum adequate models

\begin{tabular}{|c|c|c|c|c|c|}
\hline \multirow[t]{2}{*}{ Response variable } & \multicolumn{2}{|c|}{ Full model } & \multicolumn{3}{|l|}{ Minimum adequate model } \\
\hline & AIC & $d f$ & Retained terms & AIC & $d f$ \\
\hline Change in $5 \mathrm{~cm}$ latency (s) & 1851.99 & 122 & -- & -- & -- \\
\hline Change in active duration (s) & 1791.01 & 122 & oxyg, bold & 1772.8 & 137 \\
\hline Specific growth rate (\%) & 352.61 & 122 & -- & -- & -- \\
\hline Log cortisol (ng/ml) & 132.16 & 121 & risk, temp, bold, [risk*temp], [temp*bold] & 121.34 & 131 \\
\hline \multicolumn{6}{|c|}{ 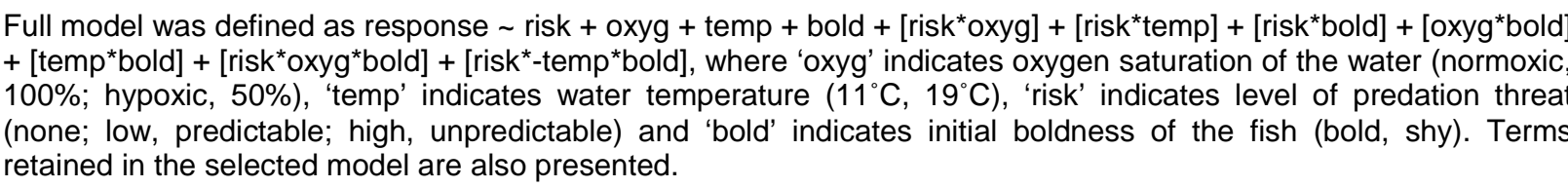 } \\
\hline
\end{tabular}

\section{Abiotic Variation}

Following the initial novel object test subjects were allowed 7 days under experimental (no, low- or highrisk) conditions before an environmental challenge, either hypoxia or increased temperature, was administered for the remaining 7 days of the test period. Hypoxia was achieved by bubbling nitrogen into the tank water; individual tanks were monitored by a temperature-compensated probe connected to an oxygen controller (Cole Parmer, Court Vernon Hills, IL, U.S.A.) linked to a solenoid that reduced the oxygen concentration to $50 \pm 1 \%$ normoxia. To prevent oxygen diffusion at the surface, floating lids were constructed from polystyrene $(89.8 \times 49.8 \mathrm{~cm})$ and covered with black plastic such that they minimized the air-water interface. Each lid had a section $(17 \times 28 \mathrm{~cm})$ that could be removed to allow feeding and predator attacks (these were used in all experiments). Each tank was checked twice per day using a hand-held oxygen probe (Seven Go Pro, Mettler Toledo, Leicester, U.K.) to ensure oxygen was maintained at the correct level. Temperature increases from 11 to $19^{\circ} \mathrm{C}$ were achieved using internal thermostatic heaters (Tetratec, Southampton, U.K.) held individually in each tank. Following this period, individuals were retested for boldness before being killed by concussion (see Tissue Sampling). This temperature range is considered within the tolerance limits of trout, but a change of temperature of this magnitude is known to cause a significant stress in fish (Strange et al. 1977).

\section{Tissue Sampling}

All fish were humanely killed by concussion at approximately the same time each day (1300 hours $\pm 1 \mathrm{~h}$ ) to ensure interpretation of plasma cortisol concentrations was not compromised by diel variations in cortisol secretion (Pickering \& Pottinger 1983). To ensure complete brain death, brains were immediately destroyed by pithing and all brain matter removed from the skull. Fish were weighed, and blood was 
collected into heparinized $2 \mathrm{ml}$ syringes and centrifuged at $3500 \mathrm{RPM}$ and $4^{\circ} \mathrm{C}$ for $5 \mathrm{~min}$, and the supernatant plasma frozen at $-20^{\circ} \mathrm{C}$ until further analysis. Cortisol concentrations were determined using a radioimmunoassay procedure (Pottinger \& Carrick 2001a).

Figure 1. Mean \pm SE change in the latency for (a) bold and (b) shy rainbow trout, to approach to within $5 \mathrm{~cm}$ of a novel object after exposure to no, low (predictable) or high (unpredictable) risk, and either low $\left(11^{\circ} \mathrm{C}\right)$ or high $\left(19^{\circ} \mathrm{C}\right)$ temperature. Bars that do not share a common lower case letter were significantly different (Tukey HSD: $P<0.05$ ), and these are contiguous between (a) and (b). $\mathrm{N}$ for each treatment is presented beneath the bars.

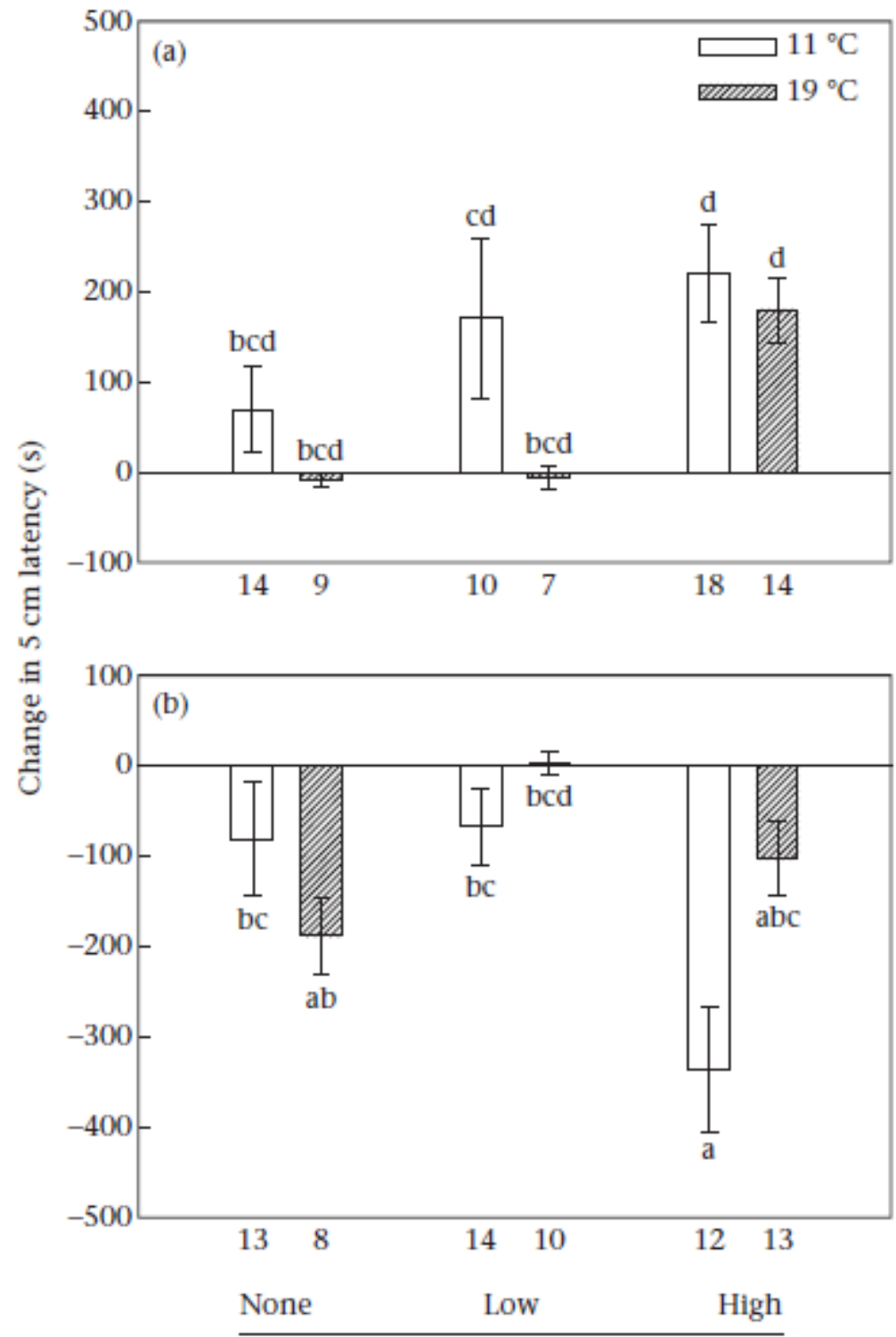

Predation risk

\section{Data Analysis}

Duration of activity was compared between bold and shy fish in the first novel object trial using a Manne-Whitney $U$ test to ensure that the measure of boldness (5 $\mathrm{cm}$ approach latency) defined distinct 
personality types according to multiple behaviours. Additionally, to determine consistency of behaviour among fish not exposed to a treatment, Kendall's coefficient of concordance was used to assess whether approach latency differed between first and second trials in the control group. Subsequently, change in behavioural measures (latency to approach within $5 \mathrm{~cm}$ of the novel object, and duration of active behaviour), specific growth rate (SGR) and plasma cortisol concentration $(\mathrm{ng} / \mathrm{ml})$ were each assessed using generalized linear models (GLM; in R, version 2.9.0, The R Foundation for Statistical Computing, Vienna, Austria, http://www.r-project.org). Specific growth rate (\%) was calculated as SGR $=100 \times\left(\log w_{f}\right.$ $\left.--\log \mathrm{w}_{\mathrm{i}}\right) \times\left(\mathrm{t}^{-1}\right)$ where $\mathrm{w}_{\mathrm{f}}=$ final weight $(\mathrm{g}), \mathrm{w}_{\mathrm{i}}=$ initial weight $(\mathrm{g})$ and $t=$ time as days in study (Höjesjö et al.

1999). Initial models contained all main terms, all two-way interactions except oxygen content*temperature, and included two three-way interaction terms: risk*oxygen content*boldness and risk*temperature*boldness. Models were reduced to minimum adequate models (Table 2): selection of terms in the models was based on minimizing Akaike's information criterion (AIC) using the stepAIC function (MASS package; Venables \& Ripley 2002). All relevant data fitted the assumptions of GLM with the exception of cortisol concentrations, which were therefore log transformed for statistical analysis. A correlation between log-transformed cortisol and SGR was tested for using a Spearman rank correlation coefficient.

Figure 2. Mean \pm SE change in latency to approach to within $5 \mathrm{~cm}$ of a novel object for bold and shy rainbow trout exposed either to normoxia $\left(100 \% \mathrm{pO}_{2}\right)$ or hypoxia $\left(50 \% \mathrm{pO}_{2}\right)$ for 7 days. Bars that do not share a common lower case letter were significantly different (Tukey HSD: $P<0.05$ ). At normoxia $N=45$ bold and 52 shy; at hypoxia $N=27$ bold and 18 shy.

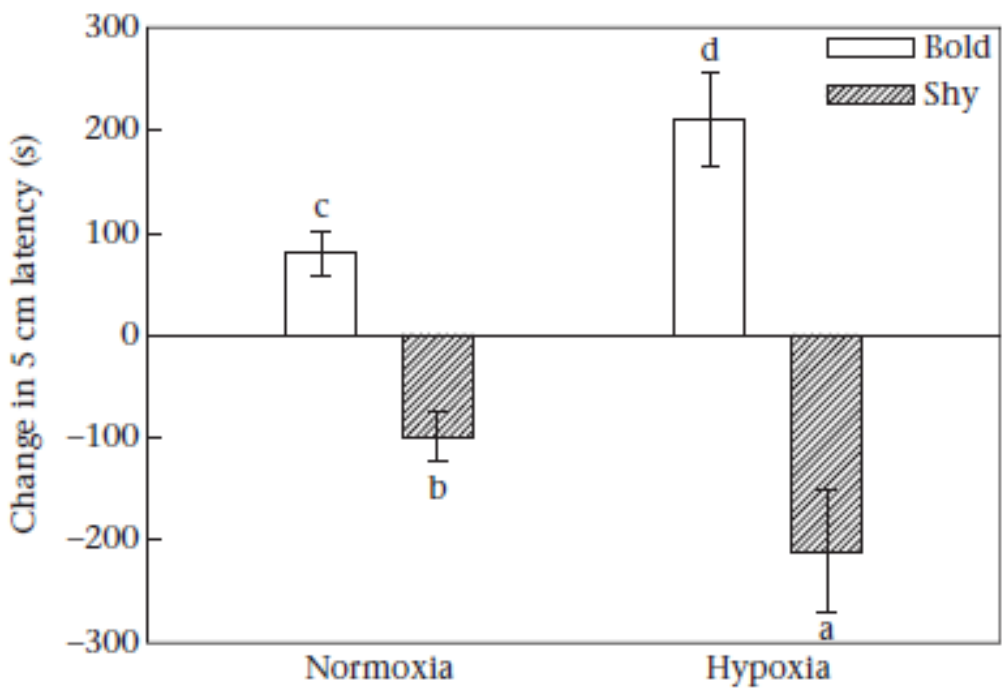

\section{Ethical Note}

The environmental variations employed in this study are well within the tolerance limits of this species. For instance, rainbow trout can inhabit waters from 0 to $25^{\circ} \mathrm{C}$ (Raleigh et al. 1984). At the temperatures used in this study 50\% normoxia is above the level considered lethal in the test species (Raleigh et al.1984) and would be experienced in natural water bodies particularly during warmer summer months (Matthews \& Berg 1997). Therefore, although these factors affect metabolic processes, the fish are known to acclimate to and tolerate such conditions. The rate of temperature change was controlled to be less than $1^{\circ} \mathrm{C} / \mathrm{h}$ and less than $5 \% \mathrm{O}_{2} / \mathrm{h}$ to allow the fish to engage homeostatic mechanisms. These 
treatments did result in physiological stress but sample sizes were kept to a minimum. The trout were not taken from a wild population but were reared for aquaculture and so our experiment did not affect natural communities. None of the fish in these experiments exhibited any adverse behavioural signs of stress. Fish skin was only taken from trout in terminal sampling experiments; thus no fish were killed just for the purpose of obtaining alarm pheromone.

Figure 3. Mean \pm SE change in duration of active behaviour of bold and shy rainbow trout in response to a novel object after a 14-day exposure period to variations in risk, water oxygen saturation and temperature. Bars were significantly different $(P<0.05) . N=70$ for bold and 70 for shy.

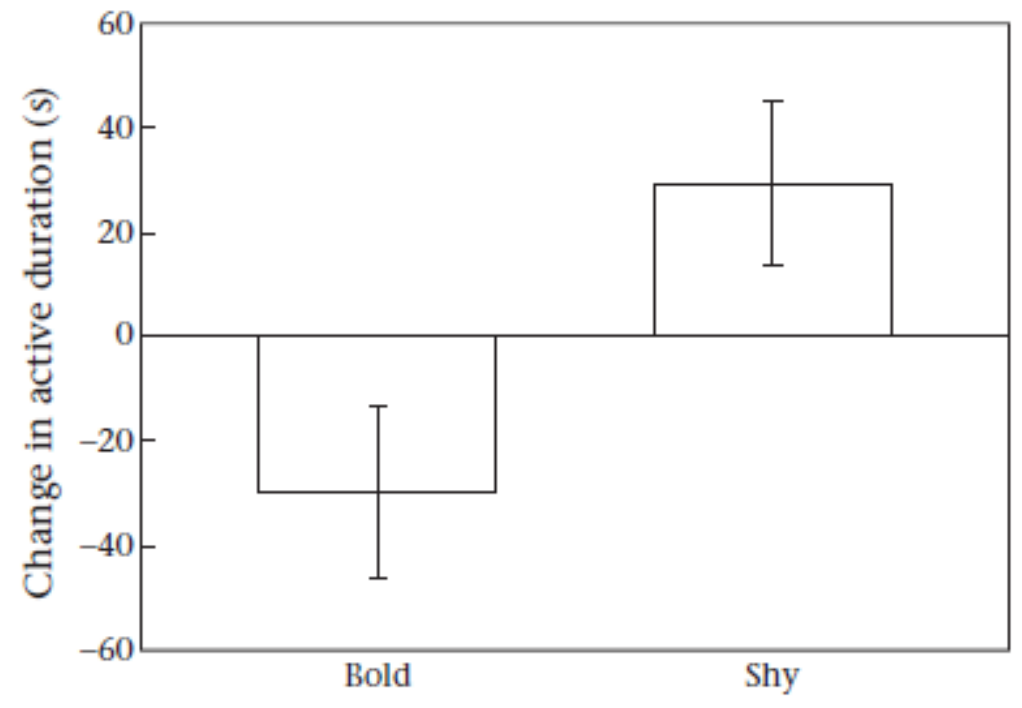

\section{RESULTS}

\section{Change in Latency}

Among the control group, there was no distinct change in latency to approach the object for bold (mean change - \pm SE -- $1.04 \pm 9.1 \mathrm{~s})$ or shy $(22.07 \pm 22.07 \mathrm{~s})$ fish, reflected in a high correlation of latency scores between the first and second trials (Kendall's $W=0.972$; P cannot be accurately calculated owing to the small sample size). Latency to approach to within $5 \mathrm{~cm}$ of the novel object changed according to a three-way interaction of risk, temperature and boldness $\left(F_{2,122}=3.77, P=0.026\right.$; Fig. 1$)$ in which bold fish generally increased approach latency, becoming shyer, and shy fish decreased latency, becoming bolder. In bold fish, the decrease in latency was maximal among those under high threat, and significantly different to the change in latency among all shy fish, save for one treatment (low threat with high temperature). There were, however, no significant differences between treatments among bold fish. Shy trout showed almost no change in behaviour at low threat, but reduced approach latency when under no threat and high threat. A maximal change in approach in shy fish was observed at high threat at the lower temperature, and this was significantly different to the change in latency for all bold fish, and the latency change in shy fish exposed to low threat and under no threat combined with low temperature.

Oxygen saturation was important in an interaction with boldness $\left(F_{1,122}=22.08, P<0.001\right)$ : bold fish became shyer and shy fish slightly bolder under normoxic conditions, and these changes were more dramatic under hypoxic conditions (Fig. 2). Finally, the main effects of oxygen saturation and initial boldness were significant: normoxia resulted in a mean \pm SE increase in approach latency of 17.84 
$\pm 18.92 \mathrm{~s}$ compared with a mean reduction in latency of $41.94 \pm 47.65 \mathrm{~s}$ for fish held in hypoxia $\left(F_{1,122}=\right.$ 4.22, $P=0.042$ ). Bold fish increased their mean \pm SE approach latency by $129.90 \pm 23.78 \mathrm{~s}$ compared with a mean reduction in latency in shy fish of $127.14 \pm 23.90 \mathrm{~s}\left(F_{1,122}=78.44, P<0.001\right)$. There were no main effects of risk $\left(F_{2,122}=1.75, P=0.179\right)$ and temperature $\left(F_{1,122}=0.46, P=0.50\right)$.

Figure 4. Mean \pm SE specific growth rate (\%) for rainbow trout exposed to no, low (predictable) or high (unpredictable) predation risk and either (a) held under normoxic $\left(\mathrm{pO}_{2}=100 \%\right)$ or hypoxic $\left(\mathrm{pO}_{2}=50 \%\right)$ conditions for 7 days in a 14-day trial; or (b) initially bold or shy in their response towards a novel object. Bars that do not share a common lower case letter were significantly different (Tukey HSD: $P<0.05$ ). $N$ for each treatment is presented above the bars.

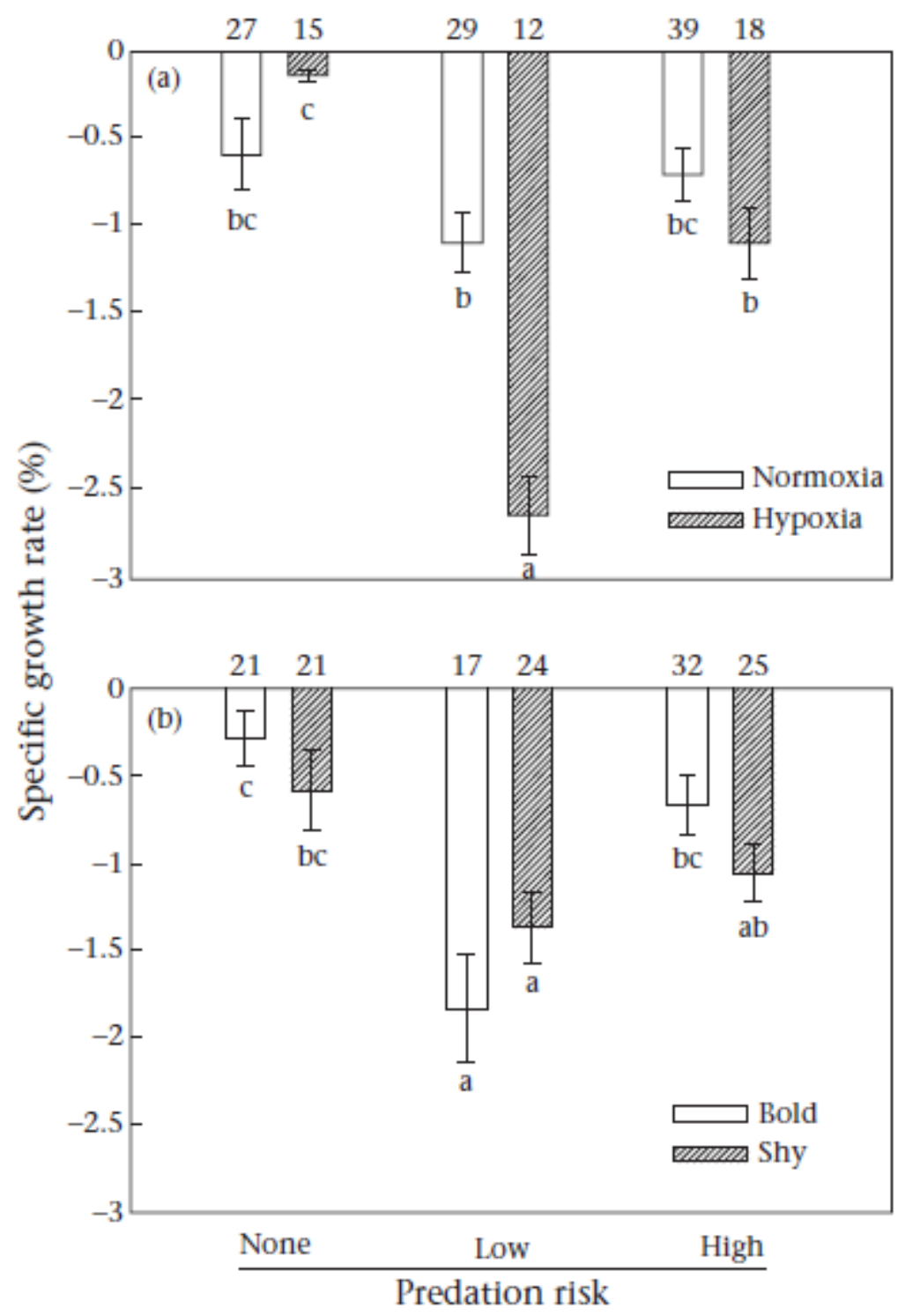

Change in Activity

Bold rainbow trout were also significantly more active (median active duration $=204.8 \mathrm{~s}$ ) than shy trout (111.7 s; $W=3078.5, N_{1}=N_{2}=70, P=0.009$ ), indicating that the selection basis used in this study discriminates between discrete bold and shy personalities. Only initial boldness influenced change in 
duration of activity: bold fish became less active while shy fish became more active. These changes were of a similar magnitude, and the difference in change between bold and shy fish was significant $\left(F_{1,137}=\right.$ 7.97, $P=0.005$; Fig. 3).

Figure 5. Median (box $=25$ th $/ 75$ th percentiles, whiskers $=10$ th $/ 90$ th percentiles, dots $=5$ th $/ 95$ th percentiles) plasma cortisol concentrations $(\mathrm{ng} / \mathrm{ml})$ for rainbow trout after a 2-week treatment period. (a) Trout were exposed to no, low (predictable) or high (unpredictable) predation threat and low $\left(11^{\circ} \mathrm{C}\right)$ or high $\left(19^{\circ} \mathrm{C}\right)$ temperature. Bars that do not share a common lower case letter are significantly different (Tukey HSD for log-transformed cortisol: $P<0.05$ ). (b) Trout were exposed to low and high temperature but separated by initially behaving boldly or shyly towards a novel object. $N$ for each treatment is presented beneath the bars. This figure illustrates raw data, but note that the data were log transformed for analysis.

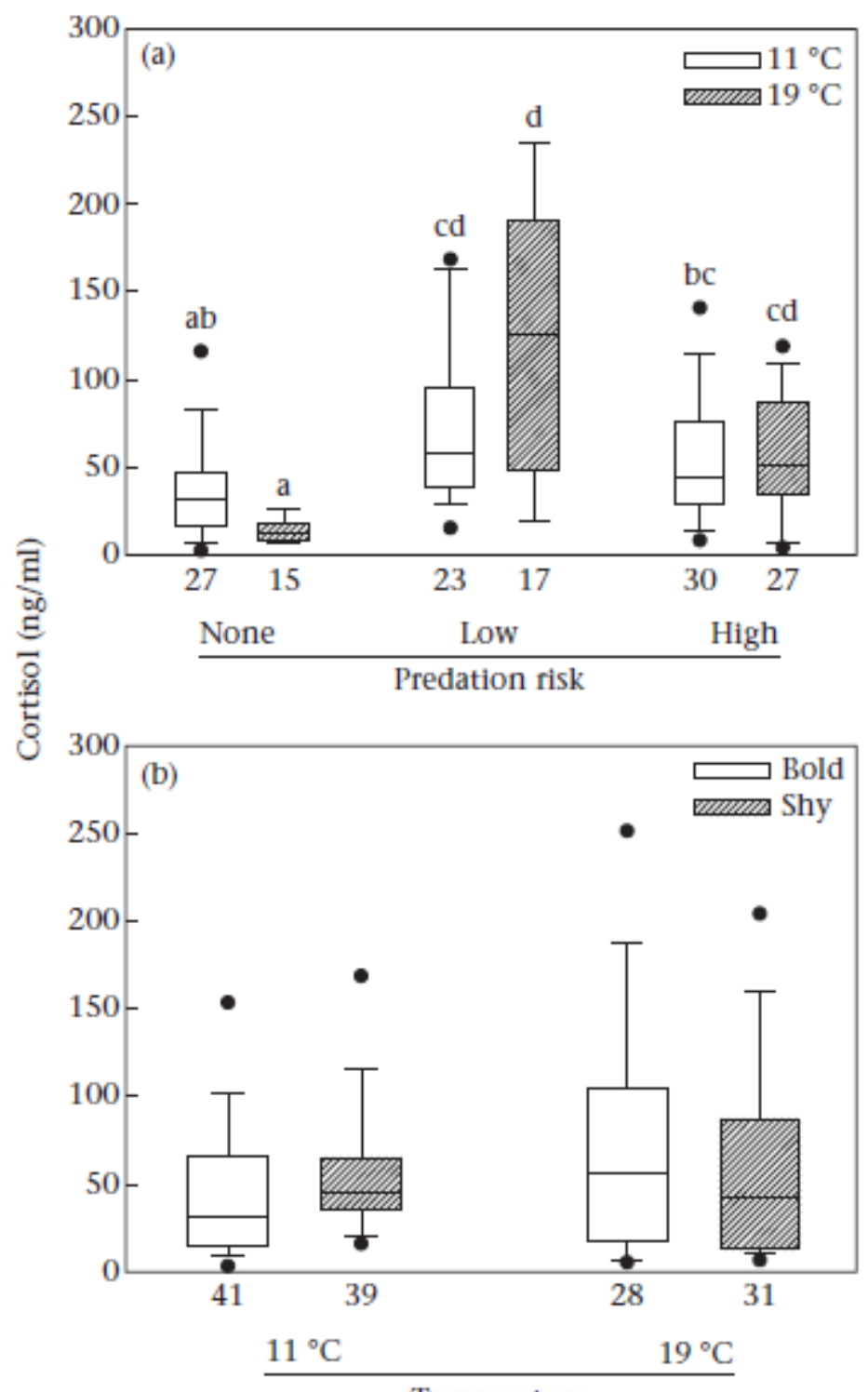

Temperature 


\section{Weight Change}

Overall $18 \%$ of trout gained weight with an increase of up to $25 \mathrm{~g}$ but the majority lost weight, evident in a negative mean SGR except for fish held under normoxia at $19^{\circ} \mathrm{C}$. Growth rate did, however, vary with treatment. Predation risk was perhaps the most influential factor (Fig. 4) and, in particular, acted synergistically with hypoxia $\left(F_{2,122}=13.89, P<0.001\right.$; Fig. $\left.4 a\right)$. In normoxic conditions, risk did not significantly influence growth rate. Under hypoxia, risk significantly reduced growth rate: high risk resulted in a 7.6-fold reduction in growth rate, while low risk resulted in an 18.4-fold reduction in growth relative to fish experiencing no threat. Bold fish also had slightly lower growth rates under predictable risk than shy fish, but this slight difference was reversed under high risk $\left(F_{22,122}=3.91, P=0.027\right.$; Fig. $\left.4 \mathrm{~b}\right)$. Importantly, growth rates were significantly lower under low threat than any other treatment except for shy fish exposed to the high threat.

The main effects of risk, oxygen availability and temperature were also significant. As would be expected, growth rate was lower at low temperature (mean \pm SE=--1.24 $\pm 0.13 \%$ ) compared with high temperature $\left(-0.49 \pm 0.09 \% ; F_{1,122} \frac{1}{4} 432.86, P<0.001\right)$, and was likewise reduced under hypoxia $(--1.20 \pm 0.18 \%)$ compared with normoxia $\left(-0.80 \pm 0.10 \% ; F_{1,122}=9.62, P=0.002\right)$. Lowest growth rate was apparent under low, predictable risk (--1.56 $\pm 0.18 \%)$, although it was also reduced in the high-risk treatment (-$0.83 \pm 0.12 \%)$ compared to no risk at all $\left(--0.43 \pm 0.14 \% ; F_{2,122}=21.28, P<0.001\right)$.

\section{Plasma Cortisol}

Median plasma cortisol concentration in control fish (no risk, $11^{\circ} \mathrm{C}$, normoxia) was $47.52(0.80-80.58)$ $\mathrm{ng} / \mathrm{ml}$ for bold fish and $42.86(19.57-130.13) \mathrm{ng} / \mathrm{ml}$ for shy fish, generally within a range previously observed among control rainbow trout ( $\varnothing$ verli et al. 2002). Log cortisol varied according to a two-way interaction between risk and temperature $\left(F_{2,131}=4.77, P=0.010\right)$ : cortisol concentrations were relatively highest in fish experiencing low risk, particularly at high temperature, and lowest where there was no risk, with those at $19^{\circ} \mathrm{C}$ the lowest of all (Fig. 5). The interaction of temperature and boldness was also significant $\left(F_{1,131}=5.17, P=0.025\right)$, whereby bold and shy fish at $11^{\circ} \mathrm{C}$ exhibited the relatively lowest and highest cortisol levels, respectively. At $19^{\circ} \mathrm{C}$ these positions were reversed and of lower magnitude. However, post hoc Tukey analysis could not determine significant differences between groups, probably because of compensation for multiple comparisons. Across all fish, cortisol levels were negatively correlated with SGR $\left(r_{\mathrm{S}}=--0.363, P<0.001\right)$.

\section{DISCUSSION}

Bold and shy personalities exhibit alternative behavioural and physiological responses to environmental stressors. The ability to alter behaviour will provide an adaptive advantage when environmental challenges are inconsistent (Dall et al. 2004). In this study both bold and shy rainbow trout were capable of responding to the presented stimuli, both seemingly becoming more intermediate in their behaviour. These changes were associated with overall reductions in the weight of individuals and activation of the stress response, particularly when exposed to low risk. Thus these personality traits are dynamic and dependent upon internal state and context.

The changes in neophobia observed here suggest fundamental differences in how bold and shy individuals are able to respond both to a single stressor (low $\mathrm{O}_{2}$ exposure) and to stressors in combination (increased risk within the context of temperature variation). Any decision to forage must be made based on the costs and benefits of doing so under predation threat, and would be mediated by the energetic state of the fish (Höjesjö et al.1999; Lima \& Bednekoff 1999; Dall et al. 2004; Quinn et al. 2012). The unpredictable regime under high threat may engender intermediate behaviour since acting too boldly 
(and risking attack) or shyly (and potentially missing foraging opportunities) may be maladaptive when predation is unpredictable. Behavioural changes were less evident at the higher temperature in shy fish, presumably because the associated increase in metabolic demand (Evans 1990) constrains the ability to be plastic. Weight loss in our fish indicated increased energetic demands either through stress- or hypoxia related reductions in foraging/assimilation (Chabot \& Dutil 1999; Bernier \& Peter 2001) or insufficient food supply. In such situations, particularly under threat, it would be adaptive to behave boldly and increase foraging rates to meet energy demands (Brown et al. 2005) but instead individuals might have been conserving energy rather than increasing effort.

In the present study, mean growth rate was negative among the control and most treatment groups with the exception of trout held under a combination of no threat and high temperature. Weight loss as a result of anorexia would often be an indicator of stress (Wendelaar Bonga 1997; Bernier \& Peter 2001). However, all fish for which data were collected had settled into experimental tanks and resumed feeding. Water quality data were also optimal for this species during the experiments. Weight change may therefore be representative of a change in feeding regime from the supplier who fed at a higher rate (3\%; personal communication) for growing on of juveniles compared with the rate we used (1--1.5\% as suggested by the feed manufacturer). This rate is consistent with our previous studies in which positive growth rates were observed (Thomson et al. 2011, 2012); therefore we followed previously successful protocols and did not expect the anomalous finding of controls losing a relatively smaller amount of weight.

Despite overall negative growth rate, the environmental treatments resulted in losses to weight beyond those observed in the control group. Hypoxia results in reduced growth in fish relative to those exposed to normoxia (Chabot \& Dutil 1999; Dabrowski et al. 2004), but clear divergence is only apparent after protracted exposure (see e.g. Dabrowski et al. 2004 for divergence in growth over an 18-week period). In the present study, trout were exposed to hypoxia only for a 1-week period but this still resulted in distinct reductions in growth rate relative to controls in some treatment groups; for instance, while average weight change in control fish was $--7.65 \%$, hypoxia resulted in weight changes of $--2.14 \%$ at no threat, $--31.66 \%$ at low threat and $--16.10 \%$ at high threat. Fish in the present study therefore exhibited divergent growth patterns, as expected, when exposed to reduced oxygen saturation. Similarly, the temperatures utilized in this study are within the tolerance limits of trout (Raleigh et al. 1984) and, alone, would not constitute a significant stressor; indeed, the increased temperature would probably contribute to greater growth rate (Solbé 1988). Rather, the change in temperature represented a challenge to homeostasis (Strange et al. 1977), resulting in an increase in metabolism and energy expenditure. Trout held at the higher temperature gained weight on average under no risk and lost the least amount under the risk regimes (7-$10 \%)$ and we believe this correctly demonstrates that fish at higher temperature had a higher metabolic rate and were more motivated to feed than the controls and fish under hypoxia at $11^{\circ} \mathrm{C}$.

Hypoxia also resulted in change to a more intermediate behaviour. With reduced dissolved oxygen fish will often risk exposure by spending more time in the relatively oxygen-rich water at the surface (Dean \& Richardson 1999); however, this may be mitigated by an increase in neophobia in the boldest animals since, owing to the increased energetic demand associated with decreased oxygen availability, the escape response will also be impaired (Kramer 1987). Thus there may exist a compromise between being bold enough to seek oxygenated water and maintaining some degree of safety. In this case, extremes of boldness may be maladaptive. Additionally, oxygen diffusion at the air--water interface was minimized in this study by floating polystyrene lids on the water. The lack of this alternative oxygen supply may have further influenced the behaviour of the fish. Divergence in behavioural responses to low oxygen saturation has been attributed to intraspecific differences in coping style (Höglund et al. 2008; Laursen et al. 2011), and therefore boldness, but this was not apparent here. Such divergence tends to be observed 
at critically low saturations (e.g. <35\%, Höglund et al. 2008), often dependent upon other stressors or internal state (Schurmann et al. 1991). Trout, however, have low tolerance to hypoxia and utilization of the wrong behavioural strategy under these conditions is often fatal (van Raaij et al. 1996; Vianen et al. 2001). It may therefore be difficult or impossible to produce a nonlethal divergence in behaviour under the conditions used in this study; since we were interested in measuring behaviour after the treatments, treatment conditions resulting in a lethal behavioural response would therefore have been unsuitable for this study. In contrast, behavioural differentiation between bold and shy animals was not observed at different temperatures under no and low threat. Phenotypic plasticity is largely constrained by the costs of gathering and maintaining sensory information regarding the environment, and the physiological changes then necessary to adjust to that environment (DeWitt et al. 1998). Considering also the energetic costs associated with high temperature (Evans 1990), behavioural change among all fish might therefore have been limited.

That the treatments had no effect on activity was surprising considering the extent of changes to temperature or oxygen saturation, which should affect metabolic rate (Evans 1990; Herbert \& Steffensen 2005; Lefrancois et al. 2005). Instead, the change in activity of these fish was associated with initial boldness and linked to their responses towards novelty, that is, shy fish became bolder and more active, while bold trout became shyer and less active. Rather than being linked with treatment, these behavioural changes may be caused by an unmeasured factor or even be commensurate with nutritional status and energetic state. Future studies should explore trade-offs in energy expenditure and intraspecific variation in the context of environmental variation in more detail. Alternatively, change in activity levels could be linked directly to the animals' habituation to their environments. Bold animals are initially active and exploratory of novel environments (Sneddon 2003; Thomson et al. 2011) but may become habituated to their environment and reduce levels of exploration; similarly, shy animals may begin to explore novel environments after a period of habituation. However, while shy trout increased overall activity levels, they showed a slight reduction in activity under control conditions but a slight increase when exposed to the treatments. This difference was not significant but suggests that, while the behaviour of bold fish may be influenced by habituation to their surrounding environment, further work will need to confirm this theory for shy fish. Regardless, an intermediate personality type may be more appropriate in the environmental conditions used in this study.

In contrast to predictions made by coping style theory (Koolhaas et al.1999), both bold and shy rainbow trout altered their behavior in a context-dependent manner, in some cases trending towards intermediate boldness, that is, not showing extreme bold or shy behaviour. Rainbow trout do exhibit behavioural and physiological traits consistent with coping style (Øverli et al. 2007, and references therein) but behavioural plasticity does not appear to be constrained to stress responsiveness (Frost et al. 2007; Ruiz-Gomez et al. 2008). Coping style may therefore be more important in determining the extent to which individuals respond to different types of stimuli, and future studies therefore need to determine the causative factors of this variation across a variety of states and contexts and relate these to natural ecology.

Cortisol concentrations in the present study represent chronic stress from daily and repeated exposures rather than a distinct response to a single stressor. Predictable predator attacks appeared to be more stressful than unpredictable attacks, and this may be linked with the ability of fish to anticipate and deal with regular events (Chen \& Tabata 2002): either the regularity of the event or the anticipation of its occurrence each day is an important factor in causing stress. Shy fish exhibited a relatively smaller change in behaviour than bold fish under the predictable risk; according to coping style theory, shy fish should be more flexible, and this result is therefore surprising but not unique (Frost et al. 2007; Basic et al. 2012; Thomson et al. 2012) and may indicate context-dependent determination of the behavioural 
flexibility of these animals. The apparent inflexibility of shy fish in this scenario may be one factor contributing to the apparent increase in stress axis activity.

Cortisol concentrations were divergent between bold and shy trout at the lower temperature, but this is not necessarily surprising as baseline cortisol levels often differ between animals of contrasting coping style (Pottinger \& Carrick 2001b; Thomson et al. 2011). The ambient temperature may simply provide an energetic environment more suitable to either behavioural phenotype dependent upon other factors. More interesting was that this effect disappeared after the temperature increase, where bold and shy fish exhibited similar cortisol profiles. That plasma cortisol concentration did not reflect the stress associated with an increase in temperature is probably due to cortisol levels falling to basal levels over time after the onset or application of a stressor (Pickering et al. 1987; Pottinger \& Moran 1993). However, high temperatures may not necessarily induce greater physiological stress responses but can provide greater scope for HPI activity (Meka \& McCormick 2005); this may explain the greater range of cortisol values exhibited at $19^{\circ} \mathrm{C}$ compared with $11^{\circ} \mathrm{C}$ in both bold and shy fish despite mean log cortisol levels remaining relatively constant. However, the mechanisms driving greater scope remain to be elucidated.

\section{Conclusions and Implications}

While individual behavioural and physiological responses to environmental stimuli are well characterized, there remains a lack of information as to how individuals respond to a variety of such challenges, and how intraspecific variation in these responses may be driven by individual differences in personality. In this study bold and shy trout responded differently to combinations of environmental pressures, with implications for how animals respond to predation pressure when under a challenge to homeostasis. Energetic and physiological state were also adversely affected by environmental stressors and by risk, with implications for fitness in a challenging environment. Understanding intraspecific variation is critical since natural environments frequently impose abiotic challenges on their inhabitants, and these may become more common or extreme because of climate change and other anthropogenic influences; a fuller understanding of these interactions can therefore inform models of individual and population fitness in increasingly stressful habitats.

\section{Acknowledgments}

J.T. was supported by a NERC CASE Ph.D. studentship (NE/F008120/1) supervised by L.S. and P.W. We are also grateful for a research grant from the Leverhulme Trust. We thank Helen Evans, Lisa Olohan and Gregor Govan for technical assistance, and also Jon Banks and Scott Weiss for the development of custom-built cameras and behavioural-analysis software, respectively. We are also grateful to the referees for their helpful comments on the manuscript.

\section{References}

Ashley, P. J., Ringrose, S., Edwards, K. L., Wallington, E., McCrohan, C. R. \& Sneddon, L. U. 2009. Effect of noxious stimulation upon antipredator responses and dominance status in rainbow trout. Animal Behaviour, 77, 403-410.

Basic, D., Winberg, S., Schjolden, J., Krogdahl, Ä. \& Höglund, E. 2012. Context-dependent responses to novelty in rainbow trout (Oncorhynchus mykiss), selected for high and low post-stress cortisol responsiveness. Physiology \& Behavior, 105, 1175-1181.

Bernier, N. J. \& Craig, P. M. 2005. CRF-related peptides contribute to stress response and regulation of appetite in hypoxic rainbow trout. American Journal of Physiology: Regulatory, Integrative and Comparative Physiology, 289, R982-R990. 
Bernier, N. J. \& Peter, R. E. 2001. The hypothalamic-pituitary-interrenal axis and the control of food intake in teleost fish. Comparative Biochemistry and Physiology, B: Biochemistry and Molecular Biology, $129,639-644$.

Brelin, D., Petersson, E., Dannewitz, J., Dahl, J. \& Winberg, S. 2008. Frequency distribution of coping strategies in four populations of brown trout (Salmo trutta). Hormones and Behavior, 53, 546-556.

Brown, C., Jones, F. \& Braithwaite, V. A. 2005. In situ examination of boldness-shyness traits in the tropical poeciliid, Brachyraphis episcopi. Animal Behaviour, 70, 1003-1009.

Brown, G. E. \& Smith, R. J. F. 1997. Conspecific skin extracts elicit antipredator responses in juvenile rainbow trout (Oncorhynchus mykiss). Canadian Journal of Zoology, 75, 1916-1922.

Brown, G. E. \& Smith, R. J. F. 1998. Acquired predator recognition in juvenile rainbow trout (Oncorhynchus mykiss): conditioning hatchery-reared fish to recognise chemical cues of a predator. Canadian Journal of Fisheries and Aquatic Sciences, 55, 611-617.

Carere, C., Drent, P. J., Privitera, L., Koolhaas, J. M. \& Groothuis, T. G. G. 2005. Personalities in great tits, Parus major: stability and consistency. Animal Behaviour, 70, 795-805.

Chabot, D. \& Dutil, J.-D. 1999. Reduced growth of Atlantic cod in non-lethal hypoxic conditions. Journal of Fish Biology, 55, 472-491.

Chapman, B. B., Morrell, L. J. \& Krause, J. 2010. Unpredictability in food supply during early life influences boldness in fish. Behavioral Ecology, 21, 501-506.

Chen, W.-M. \& Tabata, M. 2002. Individual rainbow trout can learn and anticipate multiple daily feeding times. Journal of Fish Biology, 61, 1410-1422.

Conrad, J. L., Weinersmith, K. L., Brodin, T., Saltz, J. B. \& Sih, A. 2011. Behavioural syndromes in fishes: a review with implications for ecology and fisheries management. Journal of Fish Biology, 78, 395-435.

Dabrowski, K., Lee, K.-J., Guz, L., Verlhac, V. \& Gabaudan, J. 2004. Effects of dietary ascorbic acid on oxygen stress (hypoxia or hyperoxia), growth and tissue vitamin concentrations in juvenile rainbow trout (Oncorhynchus mykiss). Aquaculture, 233, 383-392.

Dall, S. R. X., Houston, A. I. \& McNamare, J. M. 2004. The behavioural ecology of personality: consistent individual differences from an adaptive perspective. Ecology Letters, 7, 734-739.

Dean, T. L. \& Richardson, J. 1999. Responses of seven species of native freshwater fish and a shrimp to low levels of dissolved oxygen. New Zealand Journal of Marine and Freshwater Research, 33, 99-106.

DeWitt, T. J., Sih, A. \& Wilson, D. S. 1998. Costs and limits of phenotypic plasticity. Trends in Ecology \& Evolution, 13, 77-81.

Dingemanse, N. J. \& Réale, D. 2005. Natural selection and animal personality. Behaviour, 142, 11591184.

Evans, D. O. 1990. Metabolic thermal compensation by rainbow trout: effects on standard metabolic rate and potential usable power. Transactions of the American Fisheries Society, 119, 585-600. 
Frost, A. J., Winrow-Giffen, A., Ashley, P. J. \& Sneddon, L. U. 2007. Plasticity in animal personality traits: does prior experience alter the degree of boldness? Proceedings of the Royal Society B, 274, 333-339.

Herbert, N. A. \& Steffensen, J. F. 2005. The response of Atlantic cod, Gadus morhua, to progressive hypoxia: fish swimming speed and physiological stress. Marine Biology, 147, 1403-1412.

Herbert, N. A. \& Steffensen, J. F. 2006. Hypoxia increases the behavioural activity of schooling herring: a response to physiological stress or respiratory distress? Marine Biology, 149, 1217-1225.

Höglund, E., Gjøen, H.-M., Pottinger, T. G. \& Øverli, Ø. 2008. Parental stress-coping styles affect the behaviour of rainbow trout Oncorhynchus mykiss at early developmental stages. Journal of Fish Biology, 73, 1764-1769.

Höjesjö, J., Johnsson, J. I. \& Axelsson, M. 1999. Behavioural and heart rate responses to food limitation and predation risk: an experimental study on rainbow trout. Journal of Fish Biology, 55, 10091019.

Johnsson, J. I., Sernland, E. \& Blixt, M. 2001. Sex-specific aggression and antipredator behaviour in young brown trout. Ethology, 107, 587-599.

Jönsson, E., Johnsson, J. I. \& Björnsson, B. T. 1996. Growth hormone increases predation exposure of rainbow trout. Proceedings of the Royal Society B, 263, 647-651.

Koolhaas, J. M., Korte, S. M., De Boer, S. F., Van der Vegt, B. J., Van Reenen, C. G., Hopster, H., De Jong, I. C., Ruis, M. A. W. \& Blokhuis, H. J. 1999. Coping styles in animals: current status in behavior and stress-physiology. Neuroscience and Biobehavioral Reviews, 23, 925-935.

Kramer, D. L. 1987. Dissolved oxygen and fish behavior. Environmental Biology of Fishes, 18, 81-92.

Laursen, D. C., Olsén, H. L., Ruiz-Gomez, M. d. L., Winberg, S. \& Höglund, E. 2011. Behavioural responses to hypoxia provide a non-invasive method for distinguishing between stress coping styles in fish. Applied Animal Behaviour Science, 132, 211-216.

Lefrancois, C., Shingles, A. \& Domenici, P. 2005. The effect of hypoxia on locomotor performance and behavior during escape in Liza aurata. Journal of Fish Biology, 67, 1711-1729.

Lima, S. L. \& Bednekoff, P. A. 1999. Temporal variation in danger drives antipredator behavior: the predation risk allocation hypothesis. The American Naturalist, 153, 649-659.

Martínez, M. L., Landry, C., Boehm, R., Manning, S., Cheek, A. O. \& Rees, B. B. 2006. Effects of longterm hypoxia on enzymes of carbohydrate metabolism in the Gulf killifish, Fundulus grandis. Journal of Experimental Biology, 209, 3851-3861.

Matthews, K. R. \& Berg, N. H. 1997. Rainbow trout responses to water temperature and dissolved oxygen stress in two southern California stream pools. Journal of Fish Biology, 50, 50-67.

Meka, J. M. \& McCormick, S. D. 2005. Physiological response of wild rainbow trout to angling: impact of angling duration, fish size, body condition, and temperature. Fisheries Research, 72, 311-322.

van Oers, K., Klunder, M. \& Drent, P. J. 2005. Context dependence of personalities: risk-taking behavior in a social and a nonsocial situation. Behavioral Ecology, 16, 716-723. 
Olla, B. L., Davis, M. W. \& Schreck, C. B. 1995. Stress-induced impairment of predator evasion and nonpredator mortality in Pacific salmon. Aquaculture Research, 26, 393-398.

$\varnothing$ verli, Ø., Pottinger, T. G., Carrick, T. R., Øverli, E. \& Winberg, S. 2002. Differences in behaviour between rainbow trout selected for high- and low-stress responsiveness. Journal of Experimental Biology, 205, 391-395.

Øverli, Ø., Sørensen, C., Pulman, K. G. T., Pottinger, T. G., Korzan, W., Summers, C. H. \& Nilsson, G. E. 2007. Evolutionary background for stress-coping styles: relationships between physiological, behavioral, and cognitive traits in non-mammalian vertebrates. Neuroscience and Biobehavioral Reviews, 31, 396-412.

Pickering, A. D. \& Pottinger, T. G. 1983. Seasonal and diel changes in plasma cortisol levels of the brown trout, Salmo trutta L. General and Comparative Endocrinology, 49, 232e239.

Pickering, A. D., Pottinger, T. G., Carragher, J. \& Sumpter, J. P. 1987. The effects of acute and chronic stress on the levels of reproductive hormones in the plasma of mature male brown trout, Salmo trutta L. General and Comparative Endocrinology, 68, 249-259.

Pottinger, T. G. \& Carrick, T. R. 2001a. Stress responsiveness affects dominant-subordinate relationships in rainbow trout. Hormones and Behavior, 40, 419-427.

Pottinger, T. G. \& Carrick, T. R. 2001b. ACTH does not mediate divergent stress responsiveness in rainbow trout. Comparative Biochemistry and Physiology, A: Molecular \& Integrative Physiology, 129, 399-404.

Pottinger, T. G. \& Moran, T. A. 1993. Differences in plasma cortisol and cortisone dynamics during stress in two strains of rainbow trout (Oncorhynchus mykiss). Journal of Fish Biology, 43, 121-130.

Quinn, J. L., Cole, E. F., Bates, J., Payne, R. W. \& Cresswell, W. 2012. Personality predicts individual responsiveness to the risks of starvation and predation. Proceedings of the Royal Society B, 279, 1919-1926.

van Raaij, M. T. M., Pit, D. S. S., Balm, P. H. M., Steffens, A. B. \& van den Thillart, G. E. E. J. 1996. Behavioral strategy and the physiological stress response in rainbow trout exposed to severe hypoxia. Hormones and Behavior, 30, 85-92.

Raleigh, R. F., Hickman, T., Solomon, R. C. \& Nelson, P. C. 1984. Habitat Suitability Information: Rainbow Trout (Oncorhynchus mykiss). U.S. Fish and Wildlife Service Report FWS/OBS82/10.60. Washington, DC: U.S. Fish and Wildlife Service.

Ruiz-Gomez, M. d. L., Kittilsen, S., Höglund, E., Huntingford, F. A., Sørensen, C., Pottinger, T. G., Bakken, M., Winberg, S., Korzan, W. J. \& Øverli, Ø. 2008. Behavioral plasticity in rainbow trout (Oncorhynchus mykiss) with divergent coping styles: when doves become hawks. Hormones and Behavior, 54, 534-538.

Ruiz-Gomez, M. d. L., Huntingford, F. A., Øverli, Ø., Thornqvist, P.-O. \& Höglund, E. 2011. Response to environmental change in rainbow trout selected for divergent stress coping styles. Physiology \& Behavior, 102, 317-322. 
Schjolden, J., Backström, T., Pulman, K. G. T., Pottinger, T. G. \& Winberg, S. 2005. Divergence in behavioural responses to stress in two strains of rainbow trout (Oncorhynchus mykiss) with contrasting stress responsiveness. Hormones and Behavior, 48, 537-544.

Schurmann, H., Steffensen, J. F. \& Lomholt, P. 1991. The influence of hypoxia on the preferred temperature of rainbow-trout Oncorhynchus mykiss. Journal of Experimental Biology, 157, 75-86.

Shingles, A., McKenzie, D. J., Claireaux, G. \& Domenici, P. 2005. Reflex cardioventilatory responses to hypoxia in the flathead gray mullet (Mugil cephalus) and their behavioral modulation by perceived threat of predation and water turbidity. Physiological and Biochemical Zoology, 78, 744-755.

Sih, A., Bell, A. \& Johnson, J. C. 2004. Behavioral syndromes: an ecological and evolutionary overview. Trends in Ecology \& Evolution, 19, 372-378.

Smith, R. J. F. 1992. Alarm signals in fishes. Reviews in Fish Biology and Fisheries, 2, 33-63.

Sneddon, L. U. 2003. The bold and the shy: individual differences in rainbow trout. Journal of Fish Biology, 62, 971-975.

Sneddon, L. U., Braithwaite, V. A. \& Gentle, M. J. 2003. Novel object test: examining nociception and fear in the rainbow trout. Journal of Pain, 4, 431-440.

Solbé, J. 1988. Water quality. In: Salmon and Trout Farming (Ed. by L. M. Laird \& T. Needham), pp. 6986. Chichester: Ellis Horwood.

Strange, R. J., Schreck, C. B. \& Golden, J. T. 1977. Corticoid stress responses to handling and temperature in salmonids. Transactions of the American Fisheries Society, 106, 213-218.

Thomson, J. S., Watts, P. C., Pottinger, T. G. \& Sneddon, L. U. 2011. Physiological and genetic correlates of boldness: characterising the mechanisms of behavioural variation in rainbow trout, Oncorhynchus mykiss. Hormones and Behavior, 59, 67-74.

Thomson, J. S., Watts, P. C., Pottinger, T. G. \& Sneddon, L. U. 2012. Plasticity of boldness in rainbow trout, Oncorhynchus mykiss: do hunger and predation influence risk-taking behaviour? Hormones and Behavior, 61, 750-757.

Timmerman, C. M. \& Chapman, L. J. 2004. Behavioral and physiological compensation for chronic hypoxia in the sailfin molly (Poecilia latipinna). Physiological and Biochemical Zoology, 199, 835845.

Venables, W. N. \& Ripley, B. D. 2002. Modern Applied Statistics with S. 4th edn. New York: Springer.

Vianen, G. J., Van den Thillart, G. E. E. J., Van Kampen, M., Van Heel, T. I. \& Steffens, A. B. 2001. Plasma lactate and stress hormones in common carp (Cyprinus carpio) and rainbow trout (Oncorhynchus mykiss) during stepwise decreasing oxygen levels. Netherlands Journal of Zoology, 51, 33-50.

Wendelaar Bonga, S. E. 1997. The stress response in fish. Physiological Reviews, 77, 591-625.

Wilson, D. S., Coleman, K., Clark, A. B. \& Biederman, L. 1993. Shy-bold continuum in pumpkinseed sunfish (Lepomis gibbosus): an ecological study of a psychological trait. Journal of Comparative Psychology, 107, 250-260. 
Wisenden, B. D., Vollbrecht, K. A. \& Brown, J. L. 2004. Is there a fish alarm cue? Affirming evidence from a wild study. Animal Behaviour, 67, 59-67. 